\title{
Using Experimental Dynamic Modal Analysis in Assessing Structural Integrity in Historic Buildings
}

\author{
Salvatore Russo
}

Iuav University of Venice Dorsoduro 2206, Convento delle Terese, 30172, Venice, Italy

\begin{abstract}
The research optimizes the use of the dynamic modal analysis based on experimental data as a non-destructive approach in identifying the structural integrity of historic buildings. Currently dynamic modal analysis is widely used to global understand displacements of construction given their size and structure. This research proposes to simplify the ways in which to assess the structural conservation management required for historic buildings including complex monuments. The simplified approach suggested in this research is based on using ambient vibration as the excitation and the use of accelerometer sensor applied in appropriate configuration. The proposed approach, would provide a more expeditious methodology in assessing structural integrity than other methods. The research validates the results achieved with the Experimental Dynamic Modal Analysis (EDMA) methodology by comparing experimental results with those achieved with comparable FE assessment.
\end{abstract}

Keywords: Accelerometer, experimental modal analysis, integrity, modal analysis, non-destructive test.

\section{INTRODUCTION}

The need to increase the level of conservation knowledge of historic buildings is strategic and increasingly valuable from an international heritage protection perspective. The field of interest is generally related to structural control health monitoring activity in order to better understand the structural integrity of historic buildings, the conservation strategies required [1]. The research optimizes the use of dynamic modal analysis using experimental data - as a nondestructive approach in identifying the structural integrity of historic buildings.

Currently dynamic modal analysis is widely used to calibrate the FE approach or to understand global displacements of structures given their size and rigid structure [2].

The topic is very important particularly in countries characterized by the presence of significant cultural heritage, which is often protected by dedicated international organizations (like UNESCO). The protection of historic buildings can be assisted with sophisticated technology in order to provide global non-destructive assessment methodologies [3]. The research scope presented here is also particularly valuable from a preliminary inspection point of view when a plan of restoration is required.

The use of accelerometer sensor assessment technology started first in the fifties within-situ dynamic identification and the monitoring of widedams and viaducts to understand the expected global structural performance under ongoing conditions.

Recently this process has been developed overtime to assist in the structural assessment of historic buildings given

*Address correspondence to this author at the Iuav University of Venice Dorsoduro 2206, Convento delle Terese, 30172, Venice, Italy;

Tel: 0039041 2571290; Fax: 0039041 5312988; E-mail: russo@iuav.it the need to avoid any kind of invasive inspection or assessment. Early examples of this assessment methodology include the Tower of Pisa, the Traiano Column, the Colosseum and the Pantheon.

The possibility to achieve performance data on historic buildings/ monuments through the use of ambient vibration assessment gives a very interesting alternative and provides a data archive with more reliable and useful information than that derived from the numerical approach of assessment methodologies like FE.

The proposed experimental dynamic modal analysis (EDMA) is based on ambient vibration or excitation by instrumented hammer.

The use of ambient vibration also provides for the protection of building/monument masonry if cracked or damaged. The proposed assessment procedure aims only to provide a global with some outcomes obtained through the substructure analysis. As a result, the study proposes an overview of the different results using flowcharts that illustrate an outline of the assessment procedure.

The proposed research includes some case studies from buildings/monuments involved in earthquakes that occurred in Italy in 2009 and 2012, [4-6] where the aim is to detect the real stiffness and level of conservation of structural monuments particularly significant [7-9].

The research aims to provide an assessment methodology that assists in the preservation and protection of very old buildings and monuments and or to assist in the determination of the level of structural damage after exceptional events as fire, seismic actions or as an indirect effect of impact or explosion. The use of the EDMA approach could be also strategic in its ability to understand the required level of conservation required to maintain structural integrity. 
To check the reliability of the EDMA assessment procedure the analyzed cases study include different construction/monument types including churches, traditional buildings, towers and sub structure of each one when significant, [10-12]. The assessment focuses on the determination of the dynamic parameters including frequency, the coefficient of damping and modal shapes, [13]. Finally the experimental assessment is compared with a correspondent $\mathrm{FE}$ analysis to understand its reliability in evaluating the structural integrity of historic buildings.

\section{STATE OF THE ART}

The aim of this research is part of a broader and more strategic framework addressed in the literature, regarding the structural assessment of historic buildings with nondestructive techniques using dynamic modal analysis based on experimental or real data.

Concerns regarding the identification of the mechanical parameters for masonry, [14] for example are documented in research, including through the use of in-situ tests.

Other similar assessments relate to the possibility of obtaining useful information from the ambient vibration of historic buildings as in the case of the work reported in [15], involving the case of a masonry tower.

Similarly the work specified in [16] focuses in particular on the conservation status of an old chimney, and then proposes some technical evaluations in assisting the conservation of historical buildings/monuments.

The issue of structural integrity assessment is also linked to the issue of seismic vulnerability, [17] and the inherent mechanical weakness of the masonry as fragile and orthotropic material [18].

Given the importance and recent international history of seismic events, addressing the response of structural systems in masonry to seismic events [19] and the seismic protection of historic buildings, [20] is becoming increasingly important.

The manner in which the masonry is modeled is also an important consideration in structural integrity assessment, although it is not investigated directly in this research.

The approach to the modeling of the masonry is further enriched with the adoption of no-tension materials, with some models considering distinct stretches of softening in compression, others examining modeling that reproduces local interactions between bricks and mortar; right up to homogenization techniques that have in recent years represented an interesting application for a more refined investigation of the mechanical behavior of masonry materials.

Modeling assessment has also benefited from the interesting application of 3D using discrete elements in place of traditional finite elements [21]. Here a valuable support is also the evaluation of the effects related to the various computational techniques associated with individual models reported in [22] in which it is evident that these differences are not negligible.

Finally, the work presented in [23] is very close to the objectives outlined in this research and to the assessment instruments used. The cited work, albeit with reference to a single structural element a structural beam, used a timedomain approach and measured the vibrations developed in the beam, to assess damage in the element structure.

This study therefore uses the same process of measurement and vibration analysis in a time domain which is then used in experimental modal dynamic analysis.

The preliminary determination of the integrity of historic structures using dynamic modal analysis is also to verify the possible collapse mechanisms expected in the presence of a possible earthquake, with some recent research focused on the study of the behavior of macro elements, i.e. the whole of sub parts structure under analysis.

This then allows a deduction on the overall behavior of the building/monument analyzed through the study of individual parts taken as representative and illustrative of the buildings structural behavior in its entirety [24, 25].

Highlighting the prescience and value of this research area, [26-28] have provided a careful evaluation of the seismic response of historic buildings as a function of the type of structural reinforcement used and the course of retrofitting adopted.

\section{GENERAL APPROACH OF DYNAMIC MODAL ANALYSIS}

The EDMA approach takes into account methods widely employed to define modal shapes within a generic structure, deduced on the basis of the experimental data. This starts with the analysis of the signal derived from the accelerometer sensors and the translation in modal shapes. The signal of the local acceleration is transformed in displacement with a prior evaluation of the level of noise. Then the modal shapes using experimental data are calculated using the dynamic identification field already available from commercial codes, $[29,30]$. A technical review of the methodology is now further discussed.

\subsection{Signals' Analysis}

From a technical view point the design configuration depends on the channel available in the acquisition data, the type of sensors and specifically their sensitivity and the use of cable if a wireless system is not employed. From the time history of each channel the best signal-to-noise ratio $(S / N)$ is first evaluated, on the basis of the following Eq. (1):

$$
S N R=20 \ln _{10}\left[\frac{(S)}{(N)}\right]
$$

The ratio, expressed in decibel, is acceptable if $S / N>10$ $\mathrm{dB}$, while it needs filtering if $6<S / N<10 \mathrm{~dB}$. Each channel has its own threshold, calibrated on the signal that is digitalised and pre-elaborated with high pass digital filter (cut-off frequency of $0.31 \mathrm{~Hz}$ ) to remove the sensor's offset due to the instrumental variation of the signal due to loss of stability in the long term. The signals from accelerometer sensors were sampled at a frequency of $500 \mathrm{~Hz}$ per channel, with a suitable analog anti-aliasing filter and a related $100 \mathrm{~Hz}$ band pass, that is one order of magnitude higher than the noted frequencies of interest. 
The sensitivity of the accelerometer sensor applied to the historic buildings was $(1000 \mathrm{mV} / \mathrm{g})$ then $1 \mathrm{~V}=1 \mathrm{~g}$, as showed in Table 1. Table 2 summarizes the type of sensors used for structural health monitoring.

For the purpose of modal identification, signals underwent a Pass Band digital filtering between cutoff frequencies of 0.25 and $40 \mathrm{~Hz}$; each signal was subdivided into subsignals having mutual superimposition of $66 \%$ (Welch periodoram). Within a frequency resolution of $0.03 \mathrm{~Hz}$, each signal was multiplied by a Hanning time window and a frequency analysis was performed with a FFT algorithm, [1]; eigen-spectra $S_{j j}(f)$, cross-spectra $S_{i j}(f)$ and coherence functions $g_{i j}(f)$ were then determined. The mode frequencies were individuated by the simultaneous presence of the following conditions: a) presence of peaks in the eigen-spectra and cross-spectra; b) the cosine of the phase difference among three channels is approximately equal to -1 (phase opposition) or 1 (in phase); the coherence function among the three channels is approximately equal to 1 (good matching).

\subsection{Experimental Modal Shape Procedure}

Each acceleration-time graph makes reference to a single channel and to the respective monitored direction; the recording times, expressed in seconds (s) are variable with the different acquisition schemes. For each recording, the crosspower spectrum function was determined in the domain of the frequency, with reference to a number of measurement points, in order to determine the vibration modes and the respective modal parameters of frequency, damping and deformed shape [1].

A modes extraction method based on the series of data that represent the only system's response was applied on the sole input of the ambient vibration [1]. The ratio between the system's response and the stress that excites is given by matrix $H$ expressed by Equation (2):

$[H(\omega)]=\sum_{i=1}^{n} \frac{\left(v_{i}\right)\left\langle l_{i}^{T}\right\rangle}{j \omega-\lambda_{i}}+\frac{\left(v_{i}^{*}\right)\left\langle l_{i}^{H}\right\rangle}{j \omega-\lambda_{i}}$ where $n$ is the number of modes; superscripts * and $H$ denote the complex conjugate and the transposed complex conjugate respectively; $\left(v_{i}\right) \in C$ is the vector of modal shape; $\left\langle l_{i}^{T}\right\rangle \in C$ is the vector of the factors of modal participation; $\lambda_{i}$ are the poles of the system, related to the natural frequencies ( $\omega$, i.e. eigenvalues) and damping values $(\zeta)$ by means of the following relationship:

$\lambda_{i} \lambda_{i}^{*}=-\zeta_{i} \omega_{i} \pm j \sqrt{1-\zeta_{i}^{2}} \omega_{i}$

Within the representation of the dynamic system by means of the $H(\omega)$ matrix, the response of the system itself to a dynamic stress is represented in the domain of frequencies by the well known matrix $S_{y y} \in C^{m x m}$, the output spectrum:

$$
\left[S_{y y}(j \omega)\right]=[H(\omega)]\left[S_{u u}(\omega)\right][H(\omega)]^{H}
$$

where $S_{u u} \in C^{k x j}$ is the matrix that represents the stress the system is subjected to (input spectrum). While performing operational modal analysis, only the $S_{y y}$ matrix is known; assuming that the input spectrum is of unknown entity, the central term of Equation (4) is actually constant and is thus independent from the frequency:

$$
\left[S_{y y}(j \omega)\right]=[H(\omega)]\left[S_{u u}\right][H(\omega)]^{H}
$$

Equation (5) - with (2) - allows for analytical definition of the relationship between the system's response spectrum (known, since it was taken from measured quantities) and its modal parameters.

$$
\left[S_{y y}(j \omega)\right]=\sum \frac{\left(v_{i}\right)\left\langle g_{i}\right\rangle}{j \omega-\lambda_{i}}+\frac{\left(v_{i}^{*}\right)\left\langle g_{i}^{*}\right\rangle}{j \omega-\lambda_{i}^{*}}+\frac{\left\langle g_{i}\right\rangle\left(v_{i}\right)}{-j \omega-\lambda_{i}}+\frac{\left\langle g_{i}^{*}\right\rangle\left(v_{i}^{*}\right)}{-j \omega-\lambda_{i}}
$$

In Eq.(6), $\left\langle g_{i}\right\rangle$ is defined, since the input data include the only response of the system, as the operational factor of reference. Value $\left\langle g_{i}\right\rangle$ is a function of both the modal parameters of the system and the constant input spectrum. The main vibration modes were thus identified from the best match with the compared cross-spectrum functions previously yielded from the time histories of each channel.

Table 1. Sensors employed in the case studies.

\begin{tabular}{|c|c|c|c|c|c|}
\hline \multirow[b]{2}{*}{ Piezoelectric } & $\begin{array}{c}1 \mathrm{~V} / \mathrm{g} \\
\text { interval } \pm 5 \mathrm{~g}\end{array}$ & $0.1 \mathrm{~Hz}$ to $12000 \mathrm{~Hz}$ & $\approx 50 \mathrm{gm}$ & $\begin{array}{l}\text { Lightweight structural elements } \\
\text { (wood, FRP) }\end{array}$ & Laboratory test \\
\hline & $\begin{array}{c}1 \mathrm{~V} / \mathrm{g} \\
\text { interval } \pm 5 \mathrm{~g}\end{array}$ & $0.15 \mathrm{~Hz}$ to $1000 \mathrm{~Hz}$ & $\approx 200 \mathrm{gm}$ & $\begin{array}{l}\text { Heavy and lightweight structures } \\
\text { (wood, FRP Masonry, RC) }\end{array}$ & Short term monitoring \\
\hline
\end{tabular}

\begin{tabular}{|c|c|c|c|c|}
\hline Type of sensor & Sensibility & Peak deep & Transfer band & Resolution \\
\hline \hline & $1 \mathrm{~V} / \mathrm{g}$ & $2,5 \mathrm{~g}$ & $0.025-800 \mathrm{~Hz}$ & $100 \mathrm{micrograms}$ \\
\hline
\end{tabular}

Table 2. Sensor for structural health monitoring. 


\section{CASE STUDIES}

The proposed case studies reviewed to analyze the structural integrity of historic buildings were all different structures including churches, part of monumental structure (as facades or very large masonry walls), bridges and traditional buildings made with masonry. The monitored structures are shown in their whole in Fig. (1) with very short references and the motivation of the use of EDMA approach for each monument noted in the first column.

\subsection{Design of Sensor Configurations}

The design of the sensor configurations for each historic building analyzed is the first step of the EDMA assessment procedure. Details for a very complex structural monument such as the Rialto Bridge in Venice are shown in Fig. (1). The overall investigation proposed in this study is summarized in Fig. (2), with the first two columns dependent upon the type of monument with a brief description. Frequently a request for assessment can be related to the choice of macro volume parts where it may be impossible or very difficult to put sensors into the overall structure. The third column of (Fig. 2) indicates the in plane sensor configuration and their position in the correspondent macro volume.

In the case of the Palazzo Ducale (Case 1), it is important to measure the out of plane displacements of the big wall made by stone and masonry that coincide with one of two big lateral façades that characterize the very old building.

In this case the monitored façade coincides with the one assumed as a sub structure, with the sensor position able to read the lateral displacement along the height. For Case 2, the Rialto Bridge represented also in (Fig. 1), the sensor configuration has been strongly influenced by the knowledge related first of all to all the primary structure with sensors located under the arch and some with a secondary role - to understand the influence of the upper weight on the frequency and modal shapes -and was applied also to the upper buildings and to the central arch. Cases 3 and 4 can be analyzed as one since they define a similar structural form given their very large dimension sand the complex aggregation inside. They are usually called Certosa, an aggregation of several structures, and similarly in the case of the Castles. In both cases the choice of a significant substructure - that will be defined as macro volume - inside the monument-site is important toward the definition a kind of hierarchy about structural integrity.

In both cases some of the macro-volumes assumed as sub structures were isolated. In Case 3 large stairs with a corridor and annexed cells are also included. For Case 4 it is assumed that an over building is placed at the top of the buttress together with lateral components and the foundations. These were the principles that informed the in situ configuration of sensor accelerometers and consequently the expected experimental modal shapes. In Case 5 - the tower of the main church in Mirandola - due to its structural simplicity the location of sensors had to be carefully placed as illustrate in columns two and three, adopting a symmetrical configuration to optimize the use of sensors and the resulting signals' analysis.

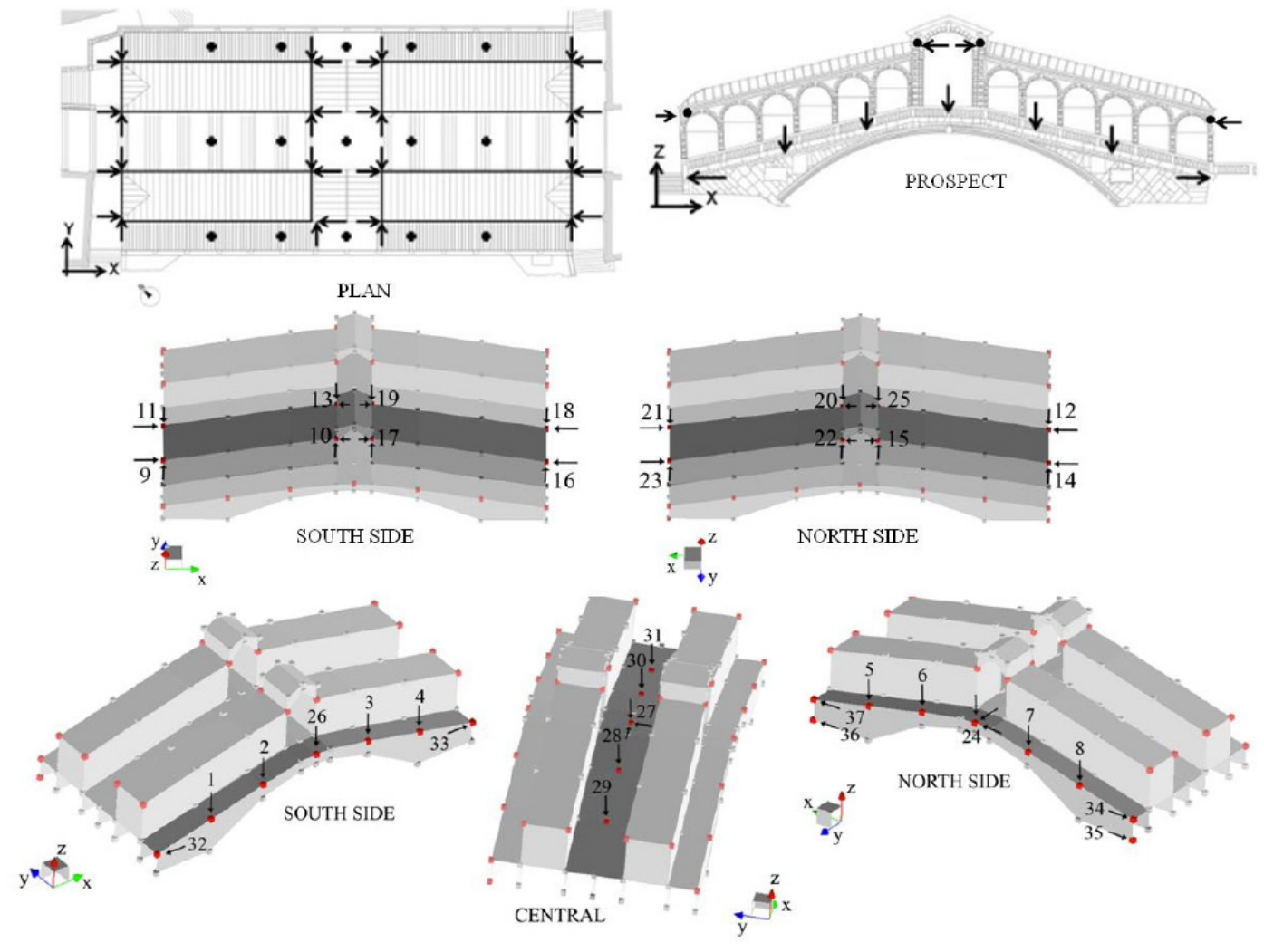

Fig. (1). Sensor configuration and direction of monitored acceleration in Rialto Bridge in Venice. 


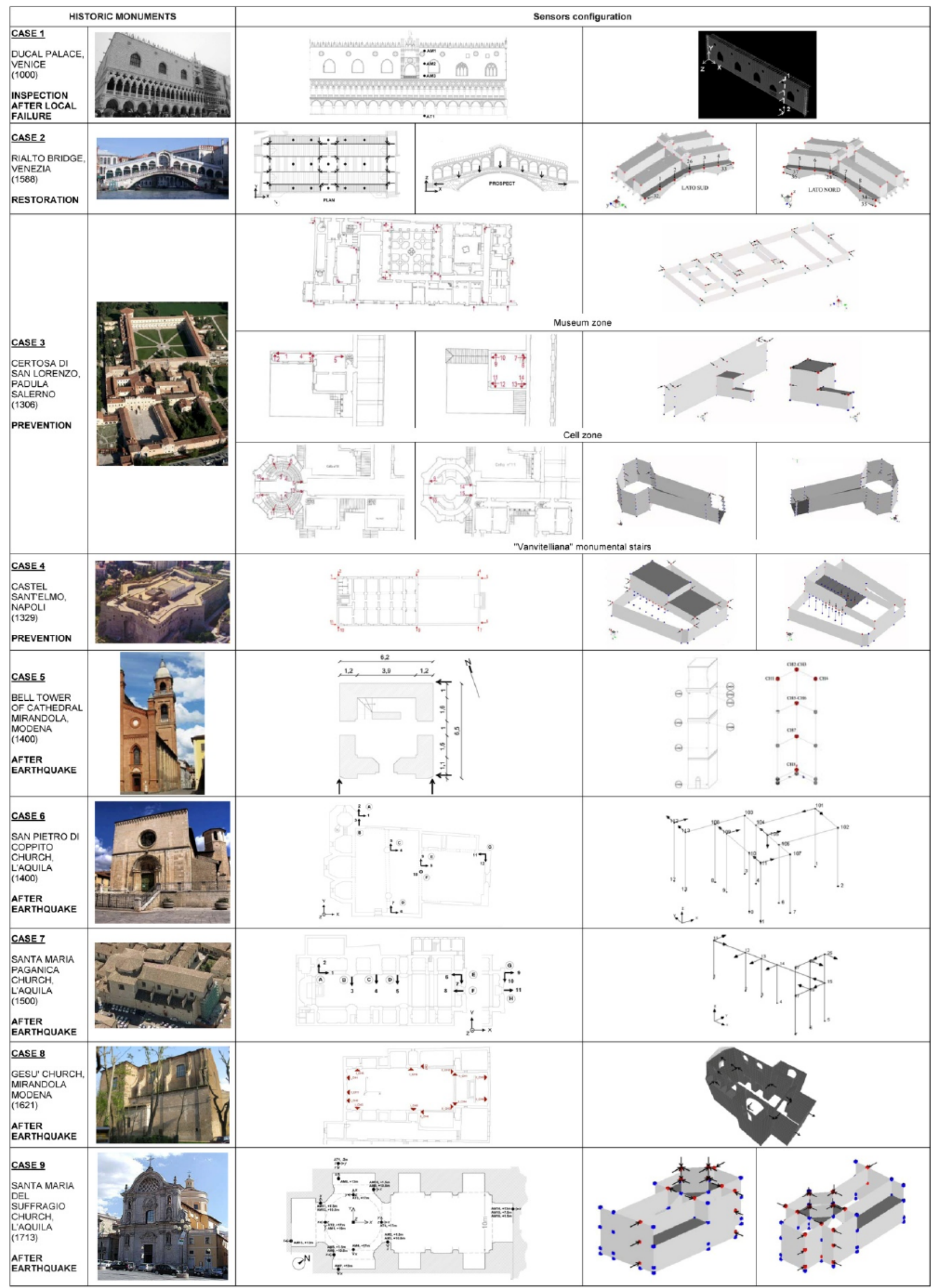

Fig. (2). Overview of the design of the sensor configuration in the analyzed cases studies. 
The cases from 6 to 9 identify the church typology since in all cases, even if in presence of very complex boundary conditions and restraint due to aggregate volume, all structures are characterized by a central space with very slender walls that coincide with the more volume weakness inside. The position of the accelerometer sensors in plane and in height is shown in the related columns.

Finally a summary of the sensor configurations is developed dependent on the characterized set of historic constructions selected; a) sub structure, b) bridge; c) monument-site; d) towers; e) churches. The type of sensor and their locations, the three-directional sensors were used at the edge of the columns in the interaction line with foundations or in complex substructures as domes. While the two directional sensors have been employed above all in masonry walls to detect first the out of plane behavior.

\section{NEW EXPEDITIOUS APPROACH}

The conceptual and technical assessment procedure utilized with EDMA starts from the need to create an approach that is reliable and expeditious. It is summarized in the following two flow charts. The first indicated in (Fig. 3) provides an outline of the process from a practical and technical view point, while the methodology is represented in Fig. (4).

Fig. (3) illustrates both the case of short and long term monitoring that can influence the quality of modal shapes derived from experimental data.

The process utilizes two kinds of excitation, the first one by means of instrumented hammer and the second by means of ambient vibration. Further phases allow the choice of signal more appropriately. The flow chart shown in (Fig. 4) describes the conceptual approach. The process restarts every time if the relation between the $f_{s s}$ value, that means the frequency of the identified sub structure (as wall, dome, covering or façade) and the value of $f_{w s}$, related on the whole structure, is not satisfied. A more reliable direction of the flow from the processing data could be divided into a bimodal identification approach. The EDMA procedure also considers validation with traditional methodology like FE analysis.

\subsection{Modal Shape and Dynamic Parameters}

The outcomes derived from the concrete application of the flow charts presented in Figs. (3 and 4) are shown in (Fig. 5) with the experimental modal shape and the dynamic parameters respectively in the third and fourth column. For each construction the experimental modal shape has been calculated with different software but with the same final results. Case 1 is reported through Excel while case 6 and 7 with Artemis while an LMS system is used for the remaining cases $[29,30]$.

Using a color scale the maximum displacements are presented in red. As expected, and can be noted in the case of the tower (Case 5), the flexural and torsional modes are dominant while in the other structures the interpretation of the shapes is as expected more complex.

In the cases 3 and 4 , the different heights in elevation between construction in the contact line represent the more significant aspect for structural integrity and at the same time the major weakness. The diagnosis for the churches is more complicated with the interaction between the façade which is heavier than the other sub parts and the connected masonry walls and is significant (see cases 6 to 9). The last column in Fig. (5) shows the more significant dynamic parameters derived from the EDMA that are the vibration modes and the correspondent frequencies and the coefficient of damping. The damping coefficient gives a measure of energy dissipation and was calculated with the Half Power Bandwidth (HPB) method, expressed by Equations (7), through (8), [1]:

$$
\begin{aligned}
& B W=\left(f_{\mathrm{i}+1}-f_{\mathrm{i}}\right) \\
& \zeta=\frac{B W}{2 f_{1}}
\end{aligned}
$$

where the bandwidth $(B W)$ is the frequency within a range of $\pm 3 \mathrm{~dB}$, corresponding to the measured (first natural) frequency, $f_{1}$. This quantifies, indirectly, the velocity from the accelerometer datum from initial frequency $f_{i}$ to final frequency $f_{i+1}$; where $f_{i}$ and $f_{i+1}$ are the two frequency limits, for calculating $B W$, of $f_{i}$ at which the amplitude is $1 / \sqrt{2}$ the resonant amplitude.

The range of variation of the damping coefficient shown in Fig. (5) is calculated on the basis of the experimental data and appears compatible with the type of structure and for those historic buildings made with masonry.

\section{RELIABILITY OF EDMA IN COMPARISON WITH THE FE ANALYSIS}

From a strategic view point the most important consequence of the application of the EDMA approach in assessing the structural integrity is related to the evaluation of its reliability. An objective comparison with a numerical model is required to support this and is proposed in Figs. (6) and (7).

The discussion between the modal shapes determined both from experimental and numerical data proposed in this study provides verification on the level of reliability of the EDMA analysis and its potential value.

Figs. (6 and 7) provide detail for the more complex churches previously noted in Case 6 and the selected type $e$ ) - that is the S.P. Coppito church in L'Aquila damaged by earthquake in 2009. In both figures from the plan and axonometric views -the left hand side provides the numerical result and the right hand side a comparison with the experimental results.

The more significant modes are influenced by the presence of asymmetrical building parts and the tower around the central part of the building of the church. The general view appears very interesting with concordance between the calculated frequencies and above all about the tendency of displacements of the singular macro-volume.

In this last case the EDMA approach can be confirmed particularly by the plan view in Fig. (6) which intercepts perfectly with the outcome of the FE analysis. In this regard it is noted that mode 1 and mode 22 give prominence to those modal shapes with displacement corresponding with the same part that received more damaged from the earthquake. This potentially suggests that the EDMA approach could be employed as a preview of the state of the structural integrity of historic buildings. 


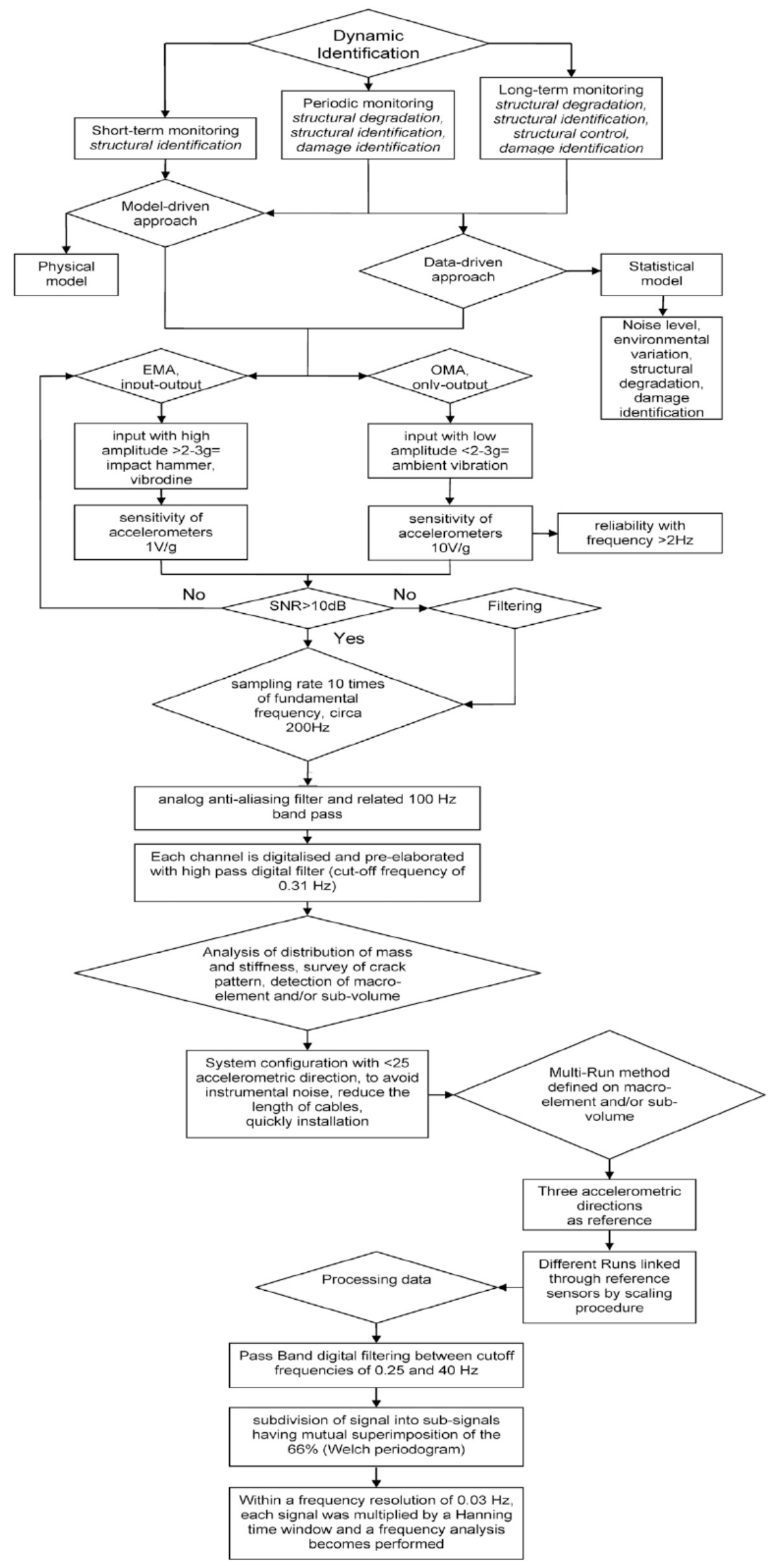

Fig. (3). Flowchart of EDMA procedure (technical aspects). 


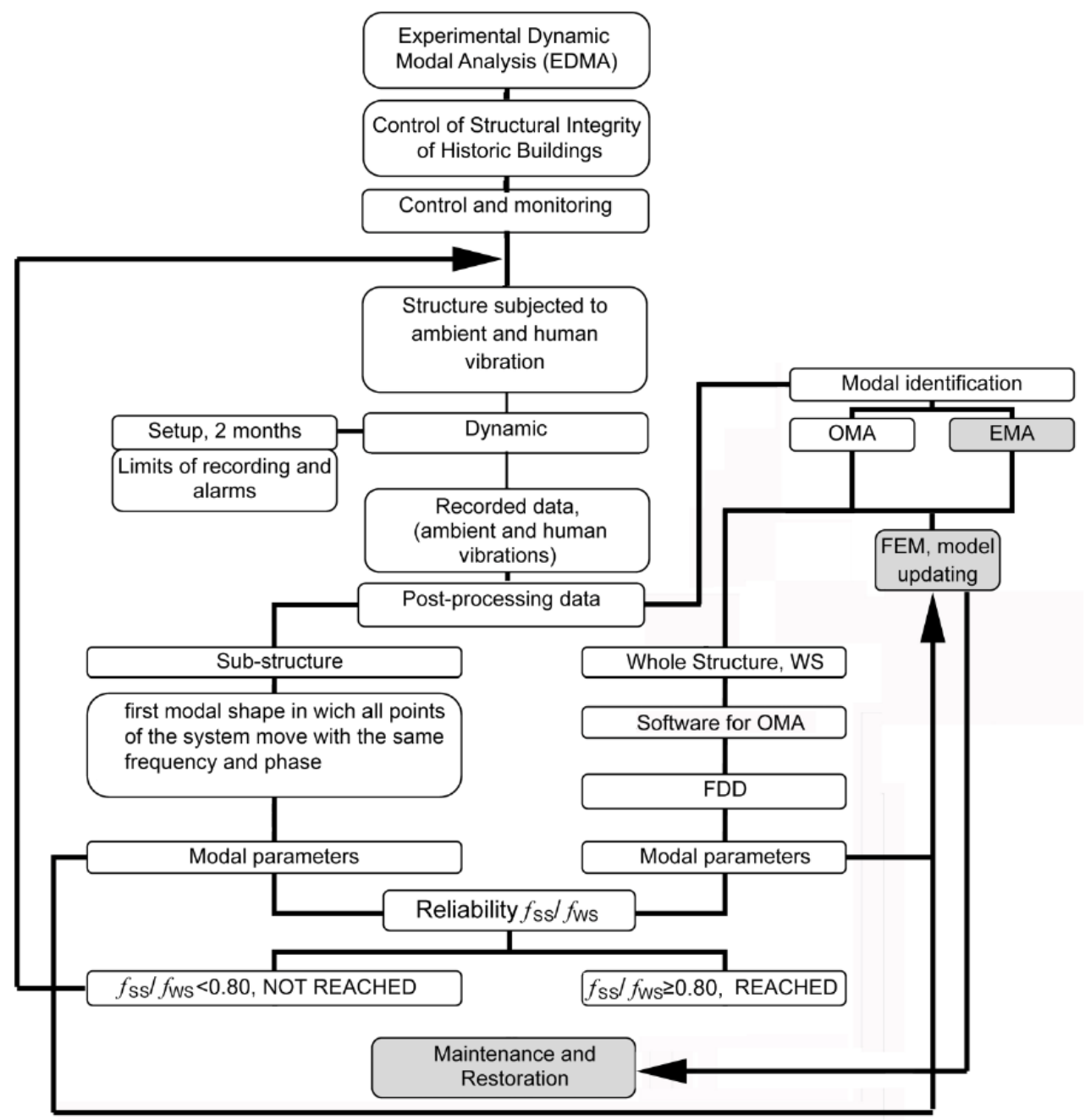

Fig. (4). Flow chart of EDMA procedure (conceptual aspects).

Concordance is then confirmed again in Fig. (7) with the axonometric comparison, particularly for the façade and the annexed tower that exhibit the same damage due to seismic action. The facade will be subject to an out of plane tendency even if more evident in the side close to the asymmetrical building placed on the right of the central part of the church. The tower laterally located will collapse along large diagonal cracks with then the loss of the top part as showed in Mode 4 and Mode 22.

\section{CONCLUSION}

On the basis of the exposed Experimental Dynamic Modal Analysis (EDMA) assessment to evaluate the structural integrity of historic buildings, the following final considerations can be proposed:

The analysis has shown that the (EDMA) assessment procedure is based on the strategic need to obtain an overall non-evasive and expeditious evaluation of the structural integrity of monumental structures, with the first experimental outcomes noted in this research appearing reliable.

The EDMA procedure is based only on experimental data without any physical vibrational impact or invasive inspection for the tested constructions.
The experimental procedure can bypass the FE approach that often is data intensive and complicated. Also the need to use reliable values for the mechanical parameters of materials is a significant aspect that strongly influences the objectivity and reliability of the common numerical approach, which could be avoided.

The use of ambient vibration employed in the cases studies is valid, even if in the presence of noise. It is also strategic from both the uniformity of the excitation - as in the case of the earthquake swarm of wind or again external action due to traffic - and also from an economic point of view.

The technical process of the EDMA procedure presented in the flow charts, optimizes the techniques by using reliable and solid signal analysis, the definition of time histories of each channel and through the domain frequencies of the correspondent matrix that define the dynamic system.

The novelty of the EDMA procedure is in the introduction of the concept of the frequency of sub structures as significant and representative variables in representing the overall structural integrity of a building/monument. The shown results provide a very good accordance with the EDMA methodology. 


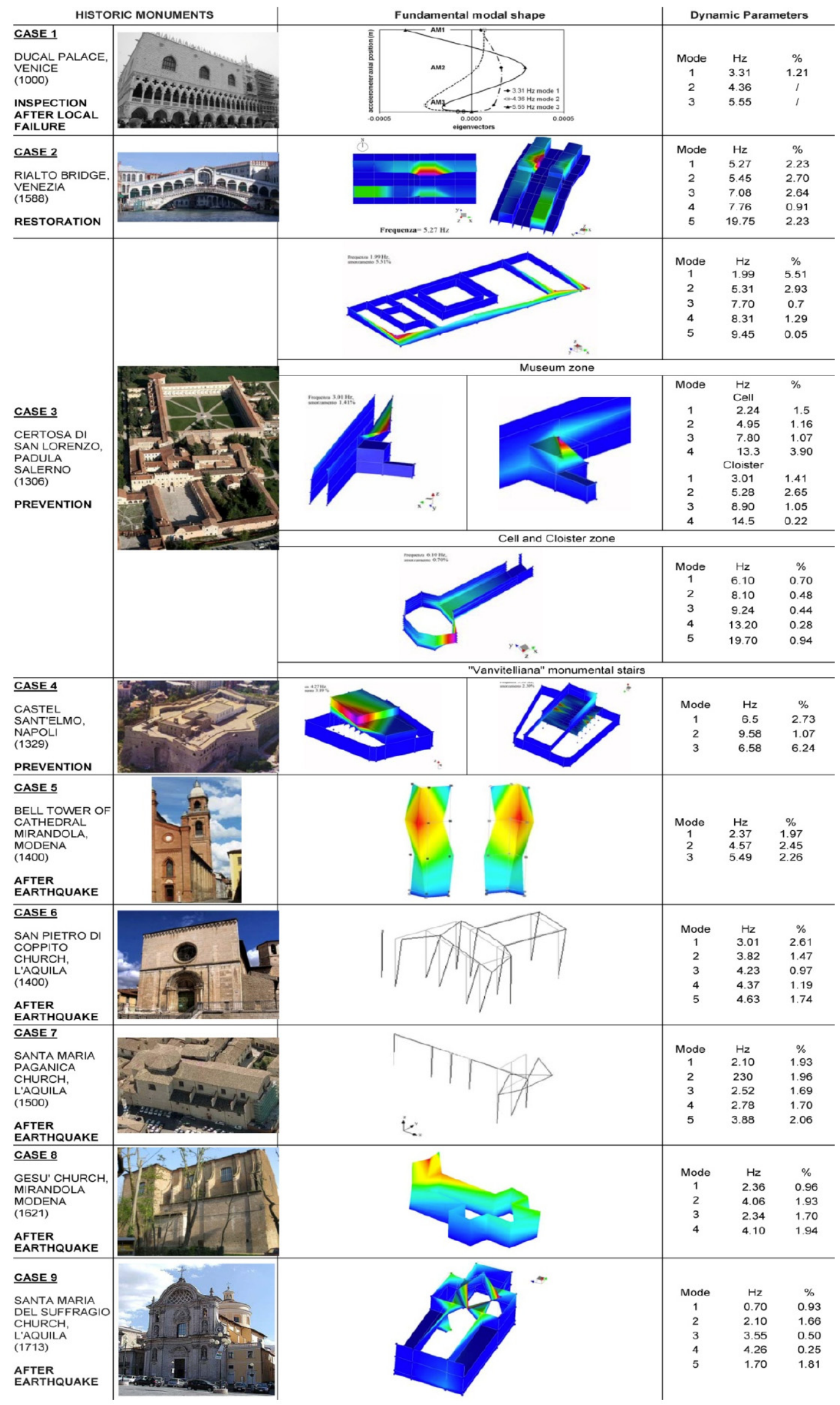

Fig. (5). Overview of the EDMA procedure applied to the all case studies and found dynamic parameters. 
FEA, mode 1 - direction $\mathrm{X}, 4.73 \mathrm{~Hz}$
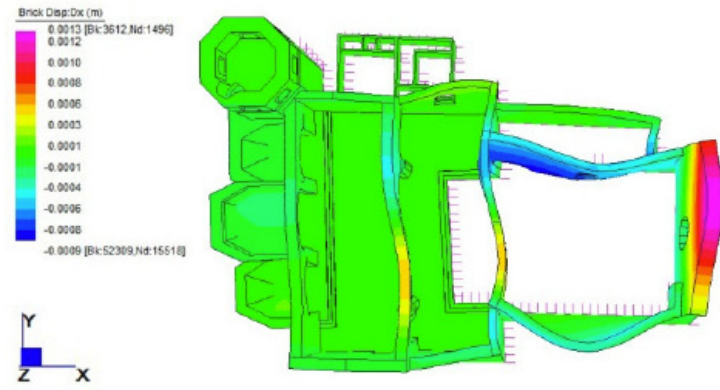

FEA, mode 4 - direction $\mathrm{Y}, 6.34 \mathrm{~Hz}$
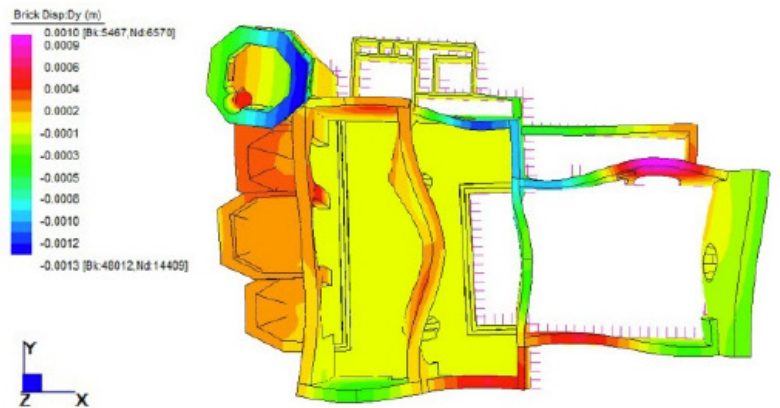

FEA, mode 22 - direction $\mathrm{X}, 16.6 \mathrm{~Hz}$
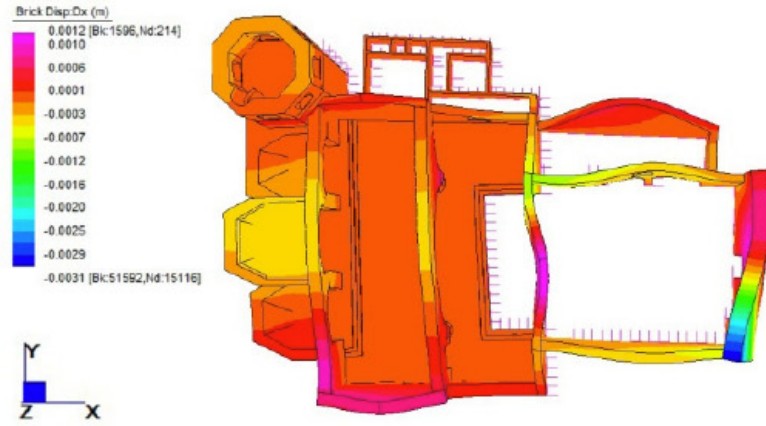

EXP, mode 2 - direction $\mathrm{X}, 3.82 \mathrm{~Hz}$

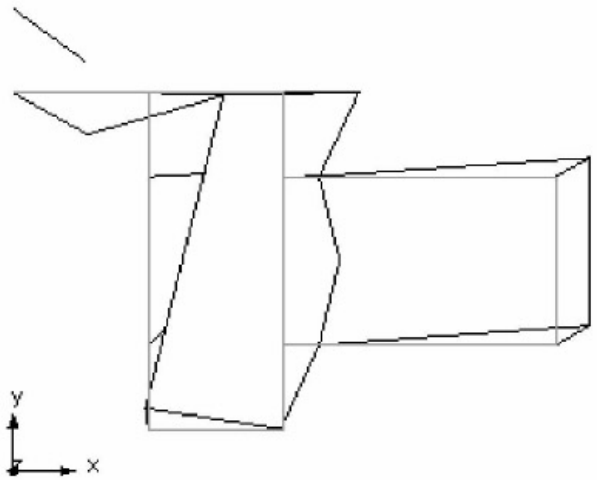

EXP, mode 5 - direction $\mathrm{Y}, 4.63 \mathrm{~Hz}$

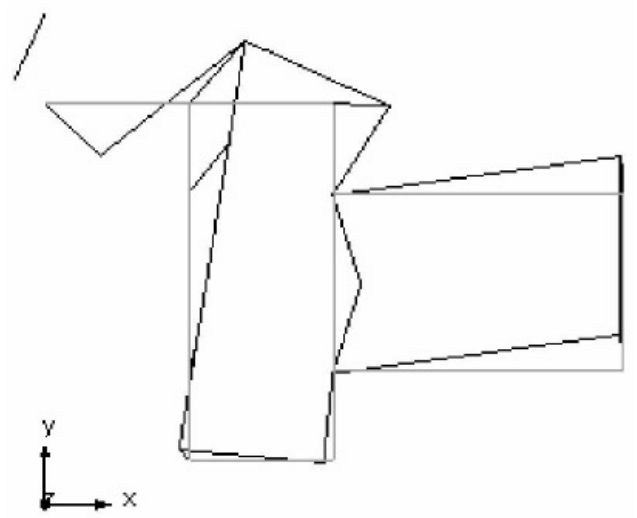

EXP, mode 10 - direction $\mathrm{X}, 16.98 \mathrm{~Hz}$

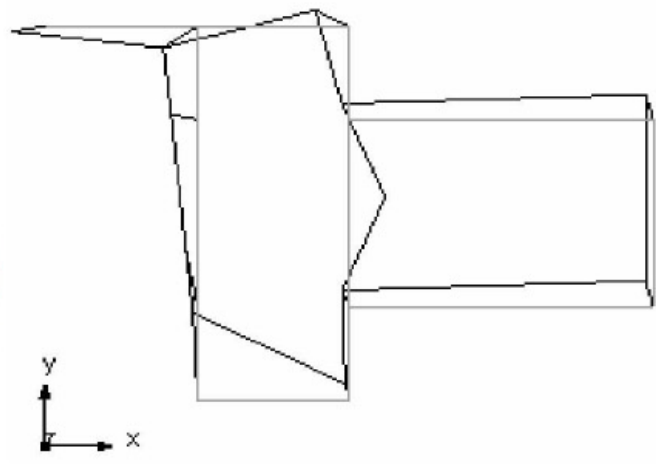

Fig. (6). Detail of Case 6 of Fig. (2). FEA/EXP comparison, plan view.

The obtained dynamic parameters appear in concordance with the expected values for historic buildings made by masonry and stone.

A final check of the reliability of the EDMA procedure was obtained through validation with the numerical data. These results confirm an agreement that is more than acceptable for the three shown modes related to the complex struc- ture such as the S.P. Coppito Church. The graphics derived from EDMA (see Figs. (6) and (7)) give above all an effective and time efficient assessment without a numerical approach that often can be unnecessarily cumbersome and redundant.

The EDMA approach also allows the assessment of the tendency of general displacements and the potential weaknesses of the historic building under dynamic actions. 
FEA, mode 1 - direction $\mathrm{X}, 4.73 \mathrm{~Hz}$
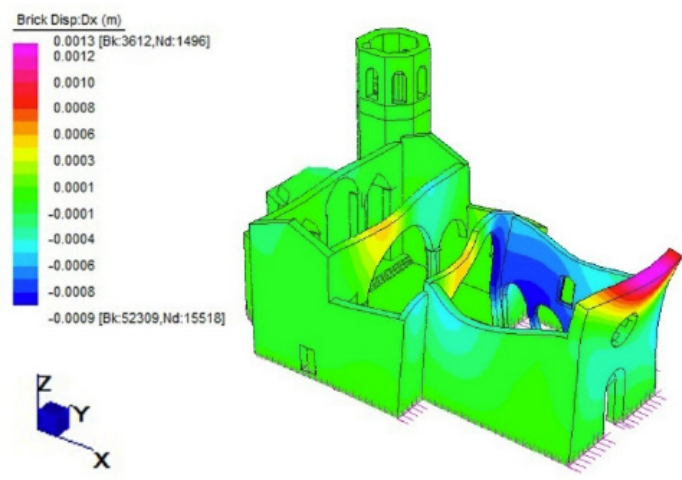

FEA, mode 4 - direction $\mathrm{Y}, 6.34 \mathrm{~Hz}$
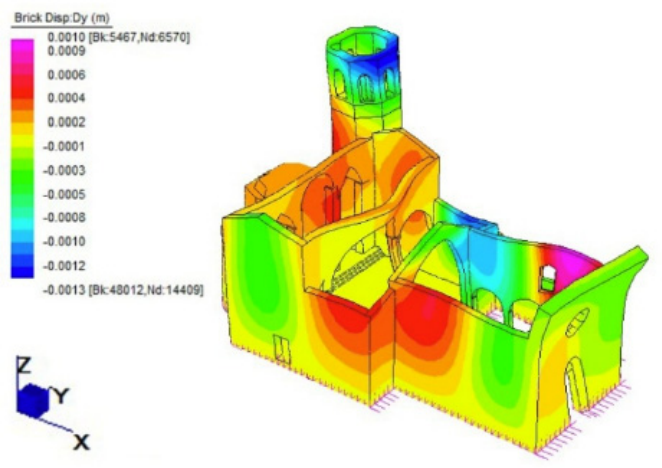

FEA, mode 22 - direction $\mathrm{X}, 16.6 \mathrm{~Hz}$
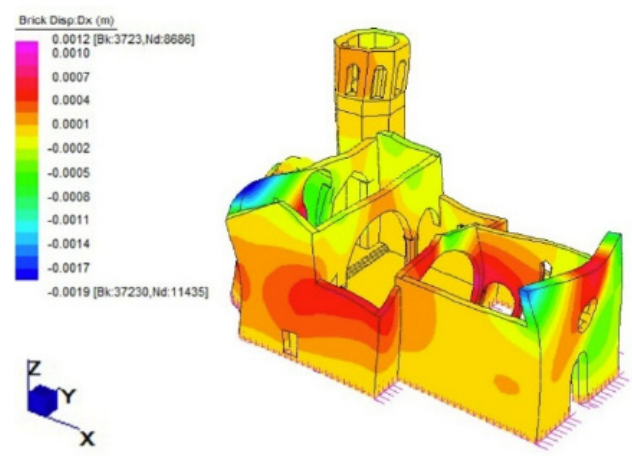

EXP, mode 2 - direction $\mathrm{X}, 3.82 \mathrm{~Hz}$

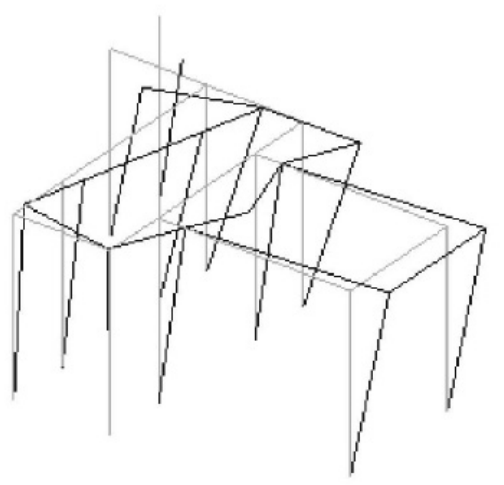

EXP, mode 5 - direction $\mathrm{Y}, 4.63 \mathrm{~Hz}$

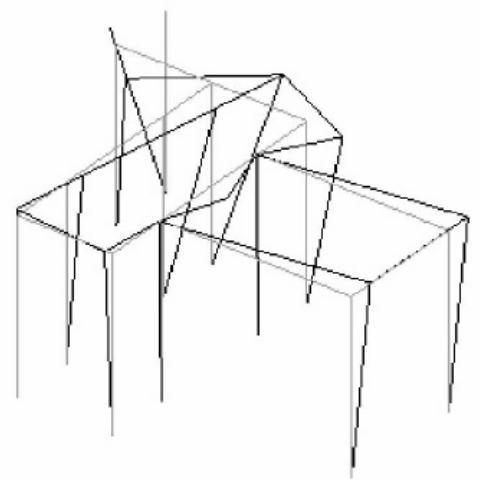

EXP, mode 10 - direction X, $16.98 \mathrm{~Hz}$

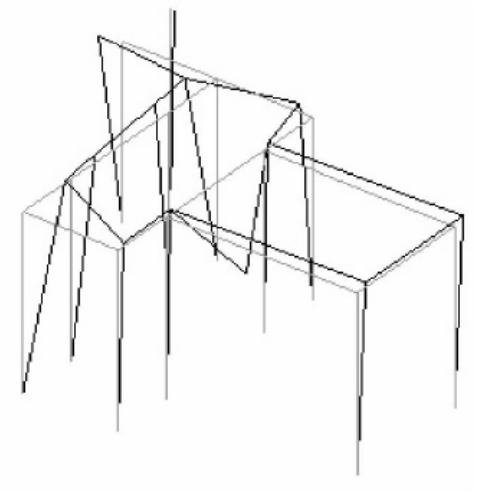

Fig. (7). Detail of Case 6 of Fig. (2). FEA/EXP comparison, axonometric view.

\section{CONFLICT OF INTEREST}

The authors confirm that this article content has no conflict of interest.

\section{ACKNOWLEDGEMENTS}

The author thanks particularly the Ph.D Giosué Boscato, the PhD students Alessandra Dal Cin and Silvia Ientile and the technicians of the Lab of Strength of Material of Iuav University of Venice. The research was also made possible thanks to the Italian Ministry of Cultural heritage (MIBACT) with a support to study the seismic behavior of some Italian Museums, and to the RELUIS organization.

\section{REFERENCES}

[1] S. Russo, "Experimental and finite element analysis of a very large pultruded FRP structure subjected to free vibration", Composite Structures Journal, vol. 94, pp. 1097-1105, 2011.

[2] A.K. Chopra, Dynamic of Structures, Theory and Applications to Earthquake engineering, Prentice Hall: $3^{\text {rd }}$ ed 2007. 
[3] G. Boscato, G. Riva, S. Russo, and F. Sciarretta, "ND tests for a first assessment of mechanical behaviour of the stone-covered façades of Palazzo Ducale in Venice", $12^{\text {th }}$ International Conference on Structural Repairs and Maintenance of Heritage Architecture 2011, September 2011 Chianciano Terme, Italy. WIT Transactions on the Built Environment 118, pp. 615-625, 2011.

[4] S. Russo, "On the monitoring of historic Anime Sante church damaged by earthquake in L'Aquila", Structural Control and Health Monitoring, vol. 20, no. 9, pp. 1226-1239, 2012.

[5] G. Milani, S. Russo, M. Pizzolato, and A.Tralli, "Seismic behavior of the San Pietro di Coppito church bell tower in L'Aquila, Italy", Open Civil Engineering Journal, vol. 6, pp. 131-47, 2012.

[6] G. Boscato, D. Rocchi, and S. Russo, "Anime Sante Church's Dome After 2009 L'Aquila Earthquake; monitoring and strengthening approaches", Advanced Materials Research, vol. 446-449, pp. 3467-85, 2012.

[7] G. Boscato, M. Pizzolato, S. Russo, and A. Tralli, "Seismic behaviour of a complex historical church in L'Aquila", International Journal of Architectural Heritage, vol. 8, pp. 718-57, 2014.

[8] G. Milani, S. Russo, M. Pizzolato, and A.Tralli, "Seismic behavior of the San Pietro di Coppito church bell tower in L'Aquila, Italy", Open Civil Engineering Journal, vol. 6, pp. 131-147, 2012.

[9] S. Russo, "Performance of a PFRP structure covering a historic building struck by an earthquake", Advanced Composites in Construction vol. 2011, pp. 51-57, 2011.

[10] S. Russo, "Testing and modelling of dynamic out-of-plane behaviour of the historic masonry façade of Palazzo Ducale in Venice, Italy", Engineering Structures, vol. 46, pp. 130-139, 2013.

[11] G. Boscato, A. Dal Cin, S. Russo, and F. Sciarretta, "Structural control health monitoring of historic damaged churches", Advanced Materials Research, vol. 838, pp. 2071-2078, 2014.

[12] G. Boscato, A. Dal Cin, G. Riva, S. Russo, and F. Sciarretta, "Knowledge of the construction technique of the multiple leaf masonry façades of Palazzo Ducale in Venice with ND and MD tests", in $4^{\text {th }}$ International Conference on Structures and Building Materials, ICSBM 2014, Advanced Materials Research, vol. 919-21, pp. 318-324, 2014.

[13] A. Dal Cin, and S. Russo, "Influence of the annex on seismic behaviour of historic churches", Engineering Failure Analysis, vol. 45, pp. 300-313, 2014.

[14] V. Sarhosis, Y.Sheng, "Identification of material parameters for low bond strength masonry", Engineering Structures, vol. 60, pp. 100-110, 2014.

[15] C. Gentile, and A. Saisi, "Ambient vibration testing of historic masonry towers for structural identification and damage assessment", Construction and Building Materials, vol. 21, pp. 1311$1321,2007$.
[16] P.B. Lourenço, "Recommendations for restoration of ancient buildings and the survival of a masonry chimney", Construction and Building Materials, vol. 20, pp. 239-251, 2006.

[17] P.G. Asteris, M.P. Chronopoulos, C.Z. Chrysostomou, H. Varum, V. Plevris, N. Kyriakides, and V. Silva, "Seismic vulnerability assessment of historical masonry structural systems", Engineering Structures, vol. 62-63, pp. 118-134, 2014.

[18] P.G. Asteris, A.D. Tzamtzis, P.P. Vouthouni, and D.S. Sophianopoulos, "Earthquake resistant design and rehabilitation of masonry historical structures", Practice Periodical on Structural Design and Construction, vol. 10, no. 1, pp. 49-55, 2005.

[19] P.G. Asteris, and I.P. Giannopoulos, "Vulnerability and restoration assessment of masonry structural systems", Electronic Journal of Structural Engineering, vol. 12, pp. 82-94, 2013.

[20] P.G. Asteris, "On the structural analysis and seismic protection of historical masonry structures", Open Construction and Building Technology Journal, vol. 2, pp. 124-133, 2008.

[21] X.L. Liu, and J. Vieira de Lemos, "A discrete element model for analysis of block masonry", EPMESC VII, In: J. Bento, Arantes e Oliviera and E. Pereira, Eds. Elsevier: Oxford, pp. 463-472, 1999.

[22] V. Giamundo, V. Sarhosis, G.P. Lignola, Y. Sheng, and G. Manfredi, "Evaluation of different computational modelling strategies for the analysis of low strength masonry structures", Engineering Structures, vol. 73, pp. 160-169, 2014.

[23] L. Majumder, and C.S. Manohar, "A time-domain approach for damagedetection in beam structures using vibration data with a moving oscillatoras an excitation source", Journal of Sound and Vibration, vol. 268, pp. 699-716, 2003.

[24] R. Vicente, D. D’Ayala, T.M. Ferrerira, S.H. Varum, A. Costa, J. M. Silva, S. Lagomarsino, "Strcutural Rehabilitation of Old Buildings" In: Seismic vulnerability and risk assessement of historic masonry buildings, Springer, Berlin, Heidelberg, pp. 307-348, 2014.

[25] Linee guida per la valutazione e riduzione del rischio simico del patrimonio culturale alienate alle nuove norme tecniche per le costruzioni (2008) - Italian guide by The Minsitery of the Cultural heritage on the reduction of the seismic risk 2008.

[26] C.Z. Chrysostomou, N. Kyriakides, A.J. Kappos, L. Kouris, E. Georgian and m. Millis, "Seismic retrofitting and Health monitoring of Scholl Buildings of Cyprus", Open Construction and Building Technology Journal, vol. 27, pp. 208-220, 2013.

[27] A. Baratta, I. Corbi, "FRP composites retrofitting for protection of monumental and ancient construction", Open Construction and Building Technology Journal, vol. 16, pp. 361-367, 2012.

[28] A. Dutta, R. Hamburgher and S. T. Bono, "Performant based analysis of historic high rise building", Open Construction and Building Technology Journal, vol. 6, pp. 361-367, 2012.

[29] Artemis Extractor Program Overview, http://www.svibs.com

[30] LMS Test.Lab: Siemens PLM Software, http://www.lmsintl.com

\author{
Received: October 07, 2014 \\ Revised: January 07, 2015 \\ Accepted: January 07, 2015
}

(C) Salvatore Russo; Licensee Bentham Open.

This is an open access article licensed under the terms of the Creative Commons Attribution Non-Commercial License (http://creativecommons.org/licenses/by-nc/3.0/) which permits unrestricted, non-commercial use, distribution and reproduction in any medium, provided the work is properly cited. 